\title{
Emerging Challenges for Numerical Simulations of Quasi-Static Collision Experiments on Laser-Welded Thin-Walled Steel Structures
}

\author{
Jani Romanoff ${ }^{1} \cdot$ Mihkel Körgesaar $^{2} \cdot$ Heikki Remes $^{1}$ \\ Received: 7 May 2020 / Accepted: 10 August 2020 / Published online: 7 December 2020 \\ (C) The Author(s) 2020
}

\begin{abstract}
This paper re-evaluates recently published quasi-static tests on laser-welded thin-walled steel structures in order to discuss the fundamental challenges in collision simulations based on finite element analysis. Clamped square panels were considered, with spherical indenter positioned at the mid-span of the stiffeners and moved along this centerline in order to change the load-carrying mechanism of the panels. Furthermore, the use of panels with single-sided flat bar stiffening and web-core sandwich panels enabled the investigation of the effect of structural topology on structural behavior and strength. The changes in loading position and panel topology resulted in different loading, structural and material gradients. In web-core panels, these three gradients occur at the same locations making the panel global responses sensitive for statistical variations and the failure process time-dependent. In stiffened panel with reduced structural gradient, this sensitivity and time-dependency in failure process is not observed. These observations set challenges to numerical simulations due to spatial and temporal discretization as well as the observed microrotation, which is beyond the currently used assumptions of classical continuum mechanics. Therefore, finally, we discuss the potential of non-classical continuum mechanics as remedy to deal with these phenomena and provide a base for necessary development for future.
\end{abstract}

Keywords Collision and grounding $\cdot$ Experiments $\cdot$ Thin-walled structure $\cdot$ Finite element analysis $\cdot$ Welding

\section{Introduction}

Ship structural design for collision and grounding accidents has gained increasing interest during last decades. These accidents are related to highly non-linear structural behavior, which can be assessed experimentally, numerically, and in some cases analytically. Despite of several analysis methods,

\section{Article Highlights}

- Quasi-static collision tests on steel stiffened and sandwich panels are explained in detail for different failure modes;

- It is shown that simultaneous gradients on load, structural, and material gradients may cause rapid failure in panels;

- Microrotations are observed at the laser welds when exposed to pure shear or tension.

Jani Romanoff

jani.romanoff@aalto.fi

1 Department of Mechanical Engineering, Aalto University, 00076 Espoo, Finland

2 Estonian Maritime Academy, Tallinn University of Technology, Tallinna 19, 93811 Kuressaare, Estonia there is still uncertainty on the true collision behavior as experiments in full-scale are extremely expensive. Thus, there is a need for reliable theoretical models, which predict the structural behavior correctly by including different mechanics for failure process and energy absorbing. In essence, the assessment consists of scenario definition (e.g., ship size, speeds, headings, structural, and loading conditions); assessment of internal (structural mechanics) and external mechanics (motions) during the collision event and assessing the consequences of the event (e.g., flooding, structural integrity, evacuation). In this framework, the current paper is limited to the internal mechanics and emerging challenges for numerical simulations. The main idea is to highlight the fact that although numerical tools are developing rapidly to assess the entire collision and/or grounding event, there remains several questions to be answered before we can use these tools with confidence.

Full-scale experiments with floating ships were first carried out by Vredeveldt and Wevers (1992) and Ohtsubo et al. (1994). The value of these experiments is the fact that they were carried out with realistic loading condition, i.e., hydrodynamic effects were combined with structural deformations 
in order to have the correct energy balance of the collision event. Realistic experiments are possible in well-defined model-scale test, with the difference that only some of the effects can be included in the models due to similitude issues (e.g., Tabri et al. 2008; Calle et al. 2020). The difficulty of these kinds of experiments is the non-linearity of the phenomenon and large number of affecting parameters (e.g., contact location, material, geometry). Therefore, these tests include uncertainty on the details of the event as different effects evolve at different temporal and spatial scales. For instance, as shown for example by Ehlers et al. (2012), Werner et al. (2014, 2015), Wadley et al. (2013), and Jones (2013), the welds can fail in collision experiments, and this weld failure has significant effect on load-carrying capacity. However, often after the experiment the detail of failure process and time of weld failure remains uncertain. This failure information is however important when experiments are compared with simulations (for such comparisons see for example, Simonsen and Törnqvist 2004; Alsos and Amdahl 2009,Alsos et al. 2009; Ringsberg 2010; Hogström and Ringsberg, 2009; Woelke and Abboud 2012; Jones 2013; Woelke et al. 2013; Körgesaar et al. 2014, Kõrgesaar et al. 2017, Kõrgesaar et al. 2018a, b). Another important aspect of experimental work is the actual damage size (i.e., fracture-induced opening size) of the ship structure affecting the stability of the vessel and possible leakage of cargo (Ringsberg 2010; Schreuber et al. 2011; Hogström and Ringsberg 2012). Moreover, because of the stochastic nature of the waves post-accidental strength is of concern. It is well known that the ultimate strength of the ship is considerably reduced after the collision or grounding (e.g., Pedersen 2010; Guedes Soares et al. 2009; Sumi 2019). The reduction of the ultimate strength is naturally the function of the amount of plastic deformation and structural integrity after accidents. The weld failure, joining stiffener to the plating, causes so-called "shadow" effect whereby longitudinals are physically intact, but they do not contribute to longitudinal strength, particularly in the case of compressive loading.

Finite element (FE) simulations of ship collision and grounding are a standard tool for scientific and engineering research (Jones 2013). FE modeling can have different levels of sophistication. The rapid Equivalent Single Layer (ESL) models (e.g., Rabczuk et al. 2004; Romanoff and Varsta 2007) are based on the idea that the structural behavior is completely defined through a single geometrical plane in which the displacements and the stress resultants are evaluated. The challenge of these models is the integration of the constitutive law during non-linear collisions event than defines the relation between displacements and the stress resultants (see Figure 1A). The most commonly used models are based on the $3 \mathrm{D}$ geometry of the structure made from shell and weld elements (Ehlers et al. 2012; Werner et al. (2014, 2015)) and in some cases the computationally intensive but very accurate models made from solid elements on component

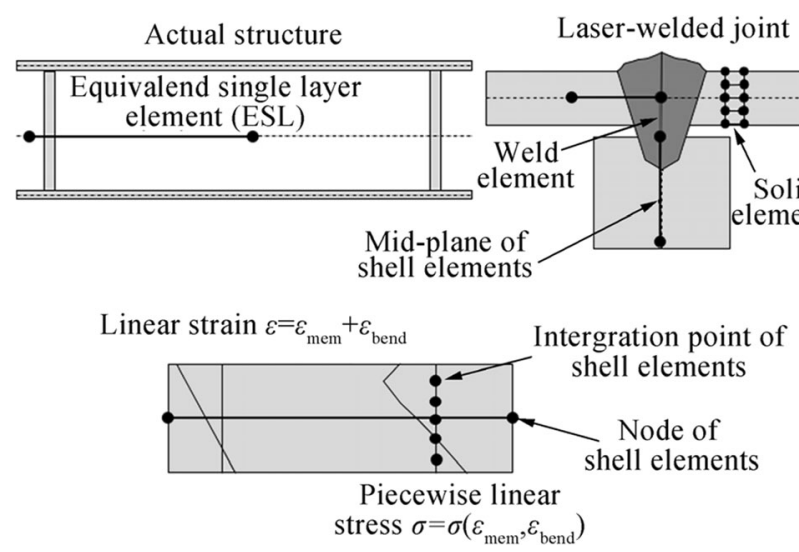

Figure 1 Structural idealizations commonly used in FE modeling from ESL shell towards full solid model and kinematics and stresses predicted by shell elements

level (see Figure 1A). For thin-walled structures, the shell elements are most common as they assume certain throughthickness behavior in terms of displacement and strains and use the non-linear constitutive expressions to compute the stresses and stress resultants (e.g., Woelke et al. 2013; Costas et al., 2019). These stress resultants (internal forces) balance with the external loading caused by structural deformations. Thereby, FE analyses allow flexibility, accuracy, and efficiency in terms of design as it can handle complex geometry, material behavior, and contact mechanics.

Due to the increase in computational capabilities, the FE simulations have been performed with ever-increasing mesh density. This allows modeling of finer details in the failure process than before. However, there is a size limit to which physical phenomena one should focus with a certain type of elements. For instance, the shell elements often follow the socalled first-order shear deformation or Kirchhoff plate theories, which assume linear longitudinal normal strains through the thickness of the element. This enables positioning nodes only in one plane of the element (see Figure 1B). This plane stress assumption means that the element cannot model through-thickness normal stress explicitly. In collision and grounding simulations, this through-thickness normal stress component is important from two perspectives (e.g., Costas et al., 2019). Firstly, during crushing and severe bending, the plate element exhibits high through-thickness stress at the contact side while at the tensile side this stress is close to zero due to lack of contact. Secondly, ductile fracture of steels is preceded by severe thinning or necking, implying significant development of through-thickness stress. In both situations, the stress triaxiality changes rapidly within the element. This triaxiality is in turn known to affect the ductile fracture significantly with the element size (see for example Wierzbicki et al. 2005; Barsoum and Faleskog 2007; Ehlers and Varsta 2009; Li and Wierzbicki 2010; Choung et al. 2012; Lou et al. 2012; Haltom et al. 2013; Körgesaar and Romanoff 2013; Dunand and Mohr 2014; Kõrgesaar and Romanoff 2014; Walters 
2014; Östlund et al. 2015). Important second issue with the shell elements is also that they usually have several integration points through the thickness and the kinematics of the element is fixed. As a result, the strains in the element are forced to follow a linear through-thickness distribution, while the longitudinal stresses can be only piecewise based on the integration point values (analogy to laminates). This piecewise behavior is not realistic for homogenous materials as the stresses in reality are smooth over the thickness. The effect of this piecewise behavior becomes significant in bending dominated problems. Thus, to understand the strain and stress development in large structures, experiments are needed that characterize the failure process in detail so that the FE analysis gets information on the acceptable level of idealization on both in strains and stresses through the thickness of elements. Furthermore, the experiments should include both membrane and bending actions (e.g., Woelke et al. 2013; Costas et al., 2019). As stresses are impossible to measure in such situations, hybrid methods would be needed where experiments (determination of strains) are complemented with numerical simulations (computation of stresses based on measured strains). In last decade, the Digital Image Correlation has become an effective tool to characterize the experimental behavior of materials, components and structures undergoing large strains (e.g., Ehlers and Varsta 2009; Ehlers et al. 2012; Hogström et al. 2009; Hoogeland and Vredevelt 2017; Kõrgesaar et al. 2018a). This strain information is essential close to the point of fracture as it allows receiving more information about localization of damage and, for example, in situ measurements of the strain state when damage happens. This is important as the history of deformation plays a crucial role in determining the point of fracture (e.g., Uppaluri et al. 2011; Frodal et al. 2020). This is also important when there are gradients in material distribution due to welding or there are hard spots in the structure due to stiffeners, i.e., stiffness gradients locally in the structure. It has been shown by several experimental and numerical papers that optimization of geometry, materials, and manufacturing process (e.g., laserwelding) of the ship structures, can result in improved crashworthy structural designs (e.g., Naar et al. 2002; Fleck and Deshpande 2004; Rubino et al. 2006; Tillbrook et al. 2007; Ehlers et al. 2012). However, the changes in materials and structures in addition to variation in loading and boundary conditions in the structure make the prediction of the nonlinear phenomena at collisions and grounding event still a challenge for FE analysis.

Motivated by above mentioned experimental and theoretical findings from open literature, this paper collects and reevaluates the experimental findings made by authors during systematic experimental campaigns (Romanoff et al. 2006; Jutila 2009; Kõrgesaar et al. 2016; Kõrgesaar et al. 2018a, b; Kõrgesaar et al. 2019) for laser-welded thin-walled structures. The findings are reflected to the FE analysis ship collisions and groundings as performed today. The main contribution of the paper is to present the situations, where the currently used main assumptions and simplifications of the Finite Element Analyses are becoming questionable. Furthermore, the usage of increasing Finite Element mesh densities and the future directions of development needs are discussed. Due to complexity of the problem, the paper is limited to internal mechanics of ship collisions and groundings, quasi-static conditions and flat panel structures to highlight relevant issues better. Two types of panels are considered. The stiffened panel structure made from normal strength steel with flat bars used as stiffeners. This structure represents the basic structural unit used in ship and offshore structures. The panel contains material gradient due to welds and structural (stiffness) gradient due to unidirectional stiffeners. The web-core steel sandwich panel is selected as the second structure, representing a double bottom or side structure of a ship. This structure has an additional structural gradient due to the rotation stiffness of the webs. The scantlings of the web-core panel are selected in the way that the initial in-plane, membrane, stiffness at zero load level is equal with the stiffened panel. Due to the geometry, the bending stiffness will be much higher in web-core sandwich panel, but the membrane behavior is assumed to dominate in large deflections. Loading position is varied in order to have gradient in out-of-plane shear forces of the panels. Due to these effects, experiments were carried out at panels, base and weld materials, and observations were made based on visual and audio observations and sensor signals. Thus, the focus of these experiments is to identify roles of loading, structural and material gradient to the non-linear response of thin-walled laser-welded steel structures. For consistency of the communication, the word "gradient" is used here to describe the sudden changes in distributions of an internal load of the statically indeterminate plate structure, structural stiffness changes due to stiffening and material properties due to laser-welding.

\section{Panel Experiments}

\subsection{General and Test Matrix}

Stiffened and sandwich panels were selected to model the two typical structural elements seen in shipbuilding (Table 1). Stiffened panels represent the most typical structural unit in the ship structures. The web-core sandwich panel is similar to the double bottom and side structures used as barriers for collisions and grounding. It also presents a family of crashworthy sandwich designs as indicated by scientific literature (Fleck and Deshpande 2004; Rubino et al. 2006; Tillbrook et al. 2007; Ehlers et al. 2012). Both stiffened and sandwich panels are laser-welded, resulting in similar welds and due to this, they have similar material gradient. Moreover, both 
Table 1 The scantlings of the stiffened and sandwich panels used in experiments

\begin{tabular}{llll}
\hline Panel & Face plate $(\mathrm{mm})$ & Web plate $(\mathrm{mm})$ & Load location \\
\hline Sandwich 1-3 & 1.5 & $3 \times 23$ & Center \\
Sandwich 4 & & & Edge at web \\
Sandwich 5 & & Edge between webs \\
Stiffened 1-4 & 3 & $3 \times 30$ & Center \\
Stiffened 5 & & & Edge \\
\hline
\end{tabular}

panels have the loaded faceplate stiffened by the webs that provide vertical support to the loaded face. This forms the structural gradient, which is similar in terms of vertical support, but considerably different in terms of rotation support to the faceplate. In web-core panel, due to the closed structure, the webs introduce significantly higher rotation support to the panels. In both panels, the loading position is changed to have different load gradients in the format of out-of-plane shear force. This load gradient is due to the statically indeterminate plate structure where the load sharing is defined by the stiffness along and transverse to stiffener directions. The details of the experiments can be found from Kõrgesaar et al. (2016); Kõrgesaar et al. 2018a, b; Kõrgesaar et al. 2019).

\subsection{Panel Experiments}

Material of specimens is standard structural steel S235JR (SSAB) with nominal values for mechanical properties as defined in standard EN 10025-2 (uniaxial test): yield strength = $235 \mathrm{MPa}(280 \mathrm{MPa}$ and $295 \mathrm{MPa}$ measured for lower and upper yield limit respectively), ultimate strength $=360 \ldots$ $510 \mathrm{MPa}$ (370 MPa measured) and elongation after fracture of $26 \%$. The panels are manufactured from plate thicknesses $1.5 \mathrm{~mm}$ and $3 \mathrm{~mm}$ by Koneteknologiakeskus in Turku, Finland. Geometry and theoretical dimensions of panels are shown in Figure 2. Sandwich panels consist of face plates connected to each other with stiffeners. Stiffener spacing is about $120 \mathrm{~mm}$ for both panels. Faceplates and stiffeners are welded together with laser stake welds.

The quasi-static indentation experiments were conducted at the Strength of Materials laboratory of Aalto University. Hydraulic force cylinder with capacity of $1 \mathrm{MN}$ was mounted to the loading frame (see Figure 3). Indentation force was measured with $1 \mathrm{MN}$ force transducer connected to bottom end of the force cylinder. Sphere indenter was mounted on force transducer. Indenter could rotate during indentation to protect force sensor from moderate bending moments.

A clamping and support design configuration allows easy assembly and removal of the specimens and is based on bolted connection (see Figures 2 and 3). A square panel is fully clamped between two support plates made from standard
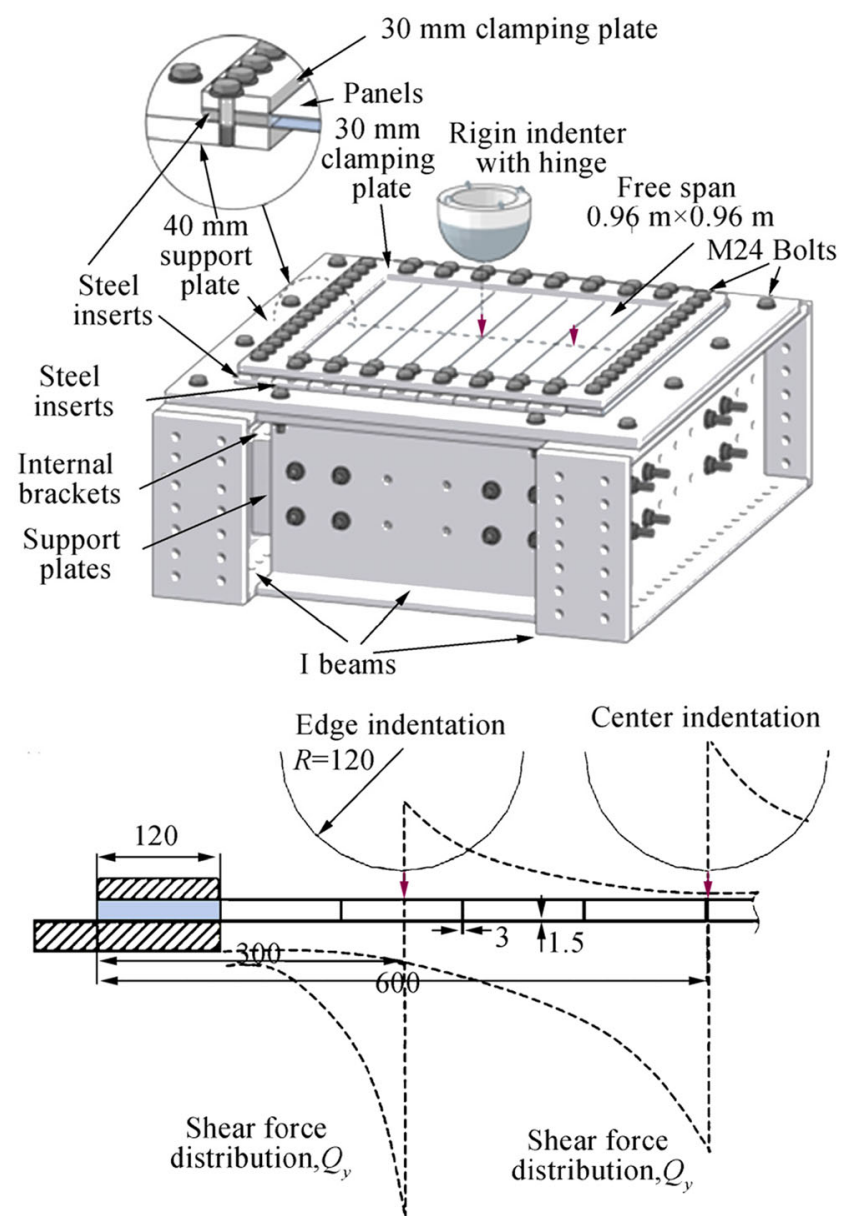

Figure 2 Test setup for panel experiments with the edge and center indentation resulting in different load gradients for out-of-plane shear force (modified from Kõrgesaar et al. 2016)

structural steel S355. The $40 \mathrm{~mm}$ thick back-support plate was bolted to an I-beam frame resting on a concrete support base. A $25 \mathrm{~mm}$ diameter, 62-hole pattern with internal threads in a back-support plate allowed edge clamping the test panels with $30 \mathrm{~mm}$ top clamping plate. Edge clamping was M24 bolts and tightening torque of $800 \mathrm{Nm}$ resulting in a total clamping force of $\sim 9 \mathrm{MN}$. Frictional clamping width in all edges was $120 \mathrm{~mm}$ resulting in a $960 \times 960 \mathrm{~mm}$ unsupported panel spans. Steel inserts were used as supports inside the $120 \mathrm{~mm}$ clamping edges. Height and width of the inserts was designed to ensure tight fit into the enclosed space. Ibeam support frame was built from HE600B (DIN 1025/EN 10034) fastened together with grade $8.8 \mathrm{M} 24$ steel bolts using four corner brackets. Additional support plates were used between brackets to adjust the beams into correct positions. Details of the stiffness of the support system and relative movement of the panels during the experiments can be found from Kõrgesaar et al. (2018b).

The load was introduced at the mid-span of the panel in the direction of stiffeners, i.e., at $x=L / 2=480 \mathrm{~mm}$ resulting in initially symmetric shear force, $Q_{x}$, distribution along the 
Figure 3 Panel dimensions with coding of the unit cells (Kõrgesaar et al. 2016)

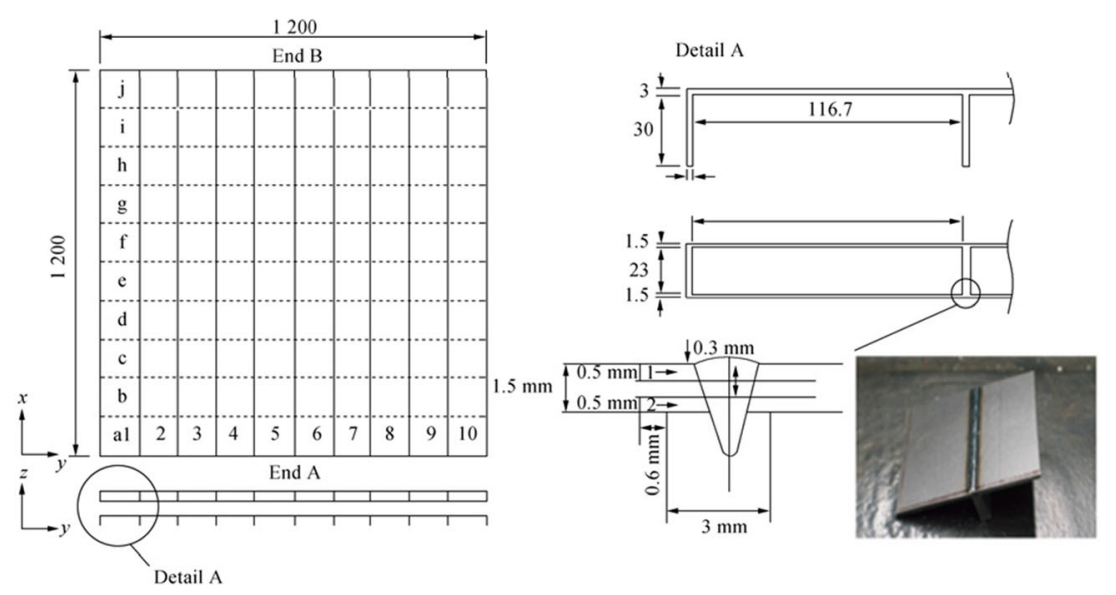

length of the panel. In this centerline, the transverse position was altered between $y=3 / 16 L, y=7 / 16 L$, and $y=L / 2$ to allow initially gradients in the shear force distribution, $Q_{y}$, transverse to the stiffener direction. This shear force is known to cause secondary bending in the unit cells of the sandwich panels, and therefore to expose the laser-stake welds to significant bending that reduces the strength of the welds (see for example Romanoff et al. 2006, 2007; Frank et al. 2013). It should be noted, that as the panels fail during the experiment in a specific manner, the load-carrying mechanism of the shear force will change and the initial assumptions of the amounts carried in $x$ - and $y$-directions become invalid. Due to this and the non-linear von Kármán strains, also the membrane and bending loading will be affected. In stiffened panel, the membrane load-carrying mechanism activates at very low load levels in comparison to sandwich panels where the bending stiffness is significantly higher and resulting in bending dominated load-carrying mechanism.

Indenter displacement was measured with HBM WA500 displacement transducer mounted between piston and cylinder and the vertical deflection of the loading frame was measured with $10 \mathrm{~mm}$ HBM WA10 displacement transducer. The amplifier is modular MGCplus by HBM with a CP 32B communications processor, 16 AP01 connection boards and 16 ML55B amplifier plug-in modules. Signal was transferred to PC via DT9834 digital-analog converter. Amplifier system settings were managed with MGCplus Assistant software. Force cylinder was displacement controlled and movement was defined with V-shaped amplitude profile, with maximum displacement being $300 \mathrm{~mm}$. The indenter velocity was $10 \mathrm{~mm} / \mathrm{min}$. The indentation was stopped in all experiments after fracture of the specimen. The unloading process was manual and not according to the Vshape amplitude defined above.

\subsection{Results and Experimental Observations}

For the stiffened panels, both force-displacement and energydisplacement curves are basically overlapping with each other when center load location is considered, while sandwich panels show larger scatter in the results (see Figure 4). The stiffened panel behavior is predictable until point of fracture where some differences are seen on residual strength and on the fracture pattern (see Figure 5). In all cases, the fracture initiates at the base material and proceeds after this within the base material or through the weld and the stiffeners, i.e., through gradients in structural stiffness and material properties. It is also interesting that the welds remain intact and position of loading does not cause surprises on the structural behavior. Thus, the load and material gradients do not affect the load-carrying mechanism of the panels to a significant extent. The sandwich panels exhibit contrasting response. The panels show very similar initial stiffness. Opposite to the global deformation seen in stiffened panels, sandwich panels deform across a few unit cells (stiffener spacings) in shear-dominated bending accompanied by acoustic emission of micro-cracking in very early stages of loading. This is a result of the secondary bending induced by the shear force, $Q_{y}$, opposite to the web-plate direction, which is results in unit cell warping. The acoustic emissions are followed by very sudden drop (rapid) in load displacement curve with rapid and loud sound, which are a result of the lower faceplate fracturing on almost its entire length just below the indenter with fracture being in weld or HAZ. The phenomena are unexpected as the tests were carried out under room temperature and in quasistatic loading. On the other hand, at these panels the load, structural and material gradients meet at the same geometrical locations. As the top face is loaded by spherical indenter, the tensile and shear loading without the effects of contact are higher in the lower faceplate. It should be also noted that in this case the shear force, $Q_{y}$, in the loaded web is very high because only few unit cells take part of the load-carrying mechanism. Thus, the stresses and strains next to the weld are much more complex and localized in sandwich panels than in stiffened panels (see Figure 6) (Kõrgesaar et al. 2019). As the loading is moved closer to the edge, the behavior in sandwich panels on initial stiffness is similar to that seen in center 


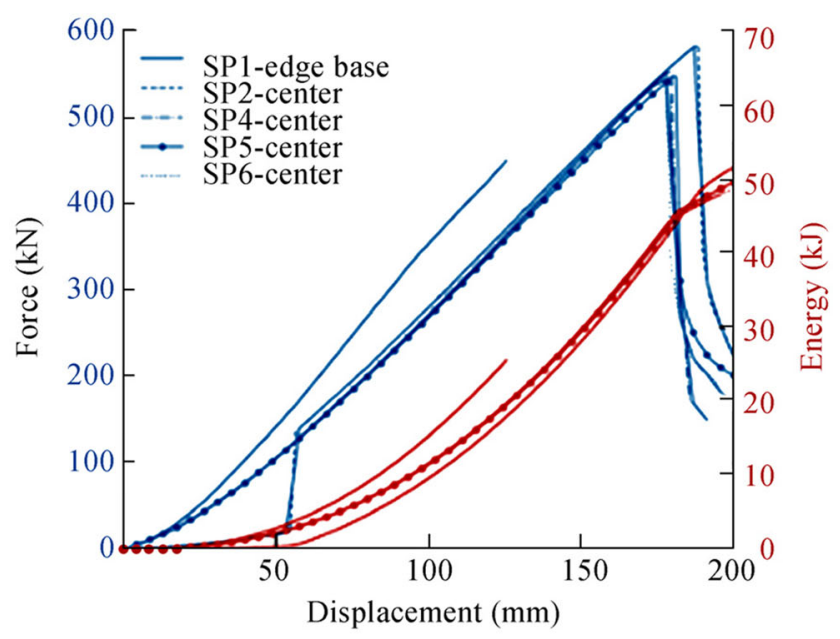

()

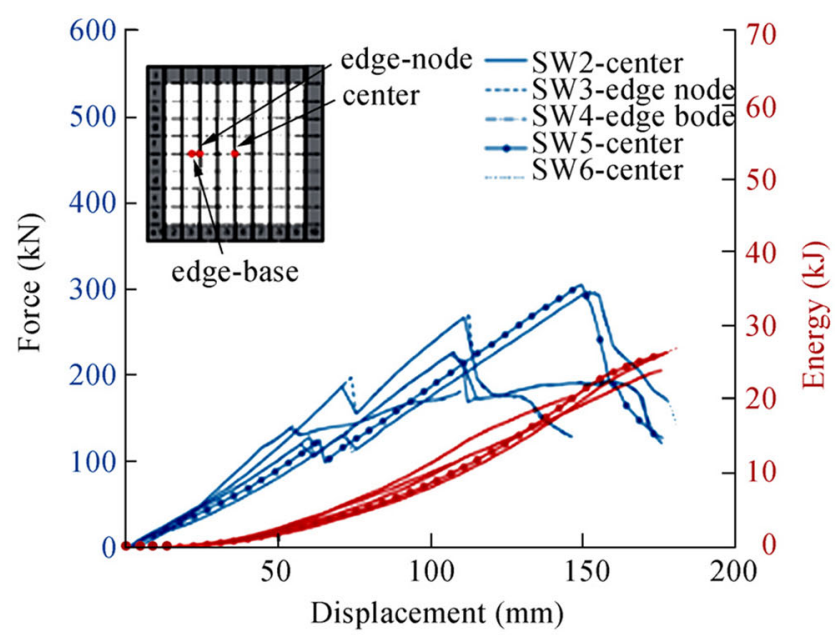

()

Figure 4 Stiffened and sandwich panel force-displacement and energydisplacement responses (modified from Kõrgesaar et al. 2016, Kõrgesaar et al. 2018a, b, Kõrgesaar et al. 2019)

load case, but the failure occurs earlier and in more dramatic manner, due to increased shear force, $Q_{y}$, gradient. This is seen as the decrease of the area below the force-displacement curve, which is an indicator of the energy absorbing capability of the structure. In a stiffened panel, such dramatic loss is not seen.

\subsection{Consequences to the Global FE Modeling Uncertainties}

The previous experimental observations mean that the discretization of the collision event in general requires very fine spatial and temporal discretization in sandwich panels, while in stiffened panels the discretization can be coarser. In addition, statistical information of weld properties in the case of sandwich panels must be included. The uncertainty of sandwich panels results from load, structural and material gradients that occur at the same locations geometrically. Thus, more accurate spatial discretization needs to account the details of the material distribution and the statistical properties of the welds in detail. Due to the closed structure of sandwich panels, the localization of damage is highly nonlinear problem in 3D. Namely, the deformations change locally due to the evolving secondary bending of the faces and webs, the contact interaction of face and web plates and within the welds (Romanoff et al. 2007; Frank et al. 2013). This means that the shell element modeling is justified on stiffened panels, but on sandwich panels, it can be used only to predict a very limited range of problems with confidence. Especially when the details of the failure are to be modeled, it seems extremely fine solid element meshes are needed at least locally. It should be kept in mind here that the sandwich panel variations are larger in terms of force-displacement curves than in stiffened panels, although both panels are made from the same material and with the same manufacturing process. Thus, it is assumed that the variation in sandwich panels is due to interacting material, structural, and loading gradients that evolve in time.

In sandwich panels and in time scale, it is clear that some effects are extremely rapid and require high temporal resolution and incorporation of strain rate effects to the material modeling. The drops in force-displacement curves are dramatic, especially when the welds fail. As the failure progresses in a rapid manner and recreates a new load-carrying mechanism while progressing, the fine temporal scale is needed to capture these shifts. It should be kept in mind from experiments that the sounds of micro-cracking were followed by loud noise for final fracture, indicating that the temporal resolution should be in the order of speed of sound in steel.

\section{Base Material Experiments}

\subsection{Test Setup}

To gain more detailed insight to the base material behavior, a set of tensile tests were performed (see also for details Kõrgesaar et al. (2018a) and Figure 7). In these quasi-static experiments strain rates were not monitored.

A standard dog-bone (DB) specimen is common type to characterize standard material stress-strain behavior. The rest of the specimens were designed with use of 3D-FEA to obtain approximately constant stress states throughout the loading history until fracture initiation. The length direction of the specimens corresponds to the direction of stiffeners in panels the specimens were extracted from. A central hole $(\mathrm{CH})$ specimen was used to characterize the material ductility under uniaxial tension (Roth and Mohr 2015). Stress triaxiality in the specimen remains nearly constant as confirmed with the preliminary FE simulations. Notched tensile (NT) specimen 
Figure 5 Failure modes for stiffened and sandwich panels (modified from Kõrgesaar et al. 2016, Kõrgesaar et al. 2018a, b, Kõrgesaar et al. 2019)
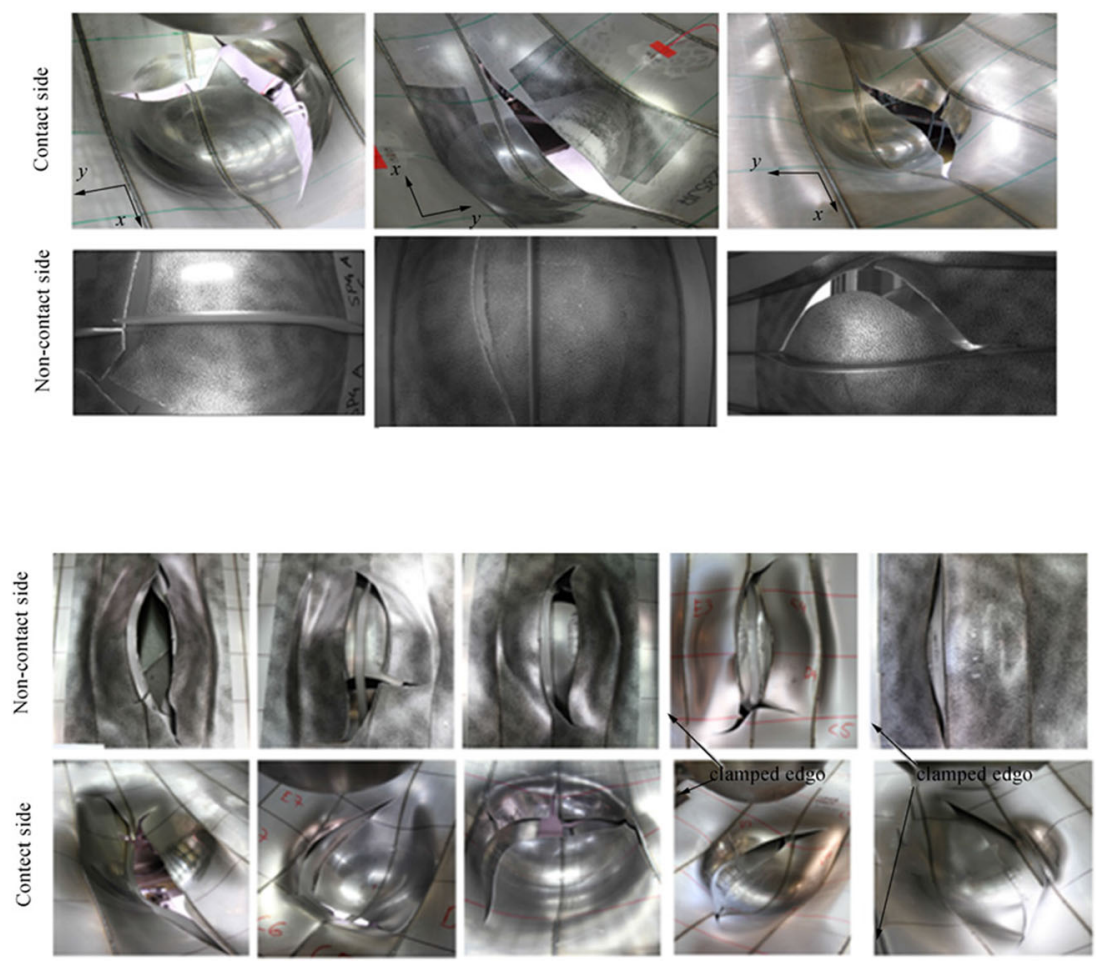

was used to describe the state of plane strain. Preliminary FE simulations showed that notch geometry has significant effect on the stress triaxiality at the point of fracture initiation and iterations were needed to obtain the final shape in which the stress state remains constant. Shear (S) specimen design shown in Figure 7(d) was motivated by Roth and Mohr
(2015), and the shape of the specimen was a result of FEbased iterations as in the case of notched specimen. Quasistatic tensile tests were performed at room temperature with $3 \mathrm{~mm}$ thick specimens using a $100 \mathrm{kN}$ MTS servo-hydraulic universal testing machine with an MTS Teststar Controller for displacement control. The crosshead velocity of the actuator
Figure 6 Stiffened and sandwich panel force-displacement and energy-displacement responses (reproduced from Kõrgesaar et al. 2018b)

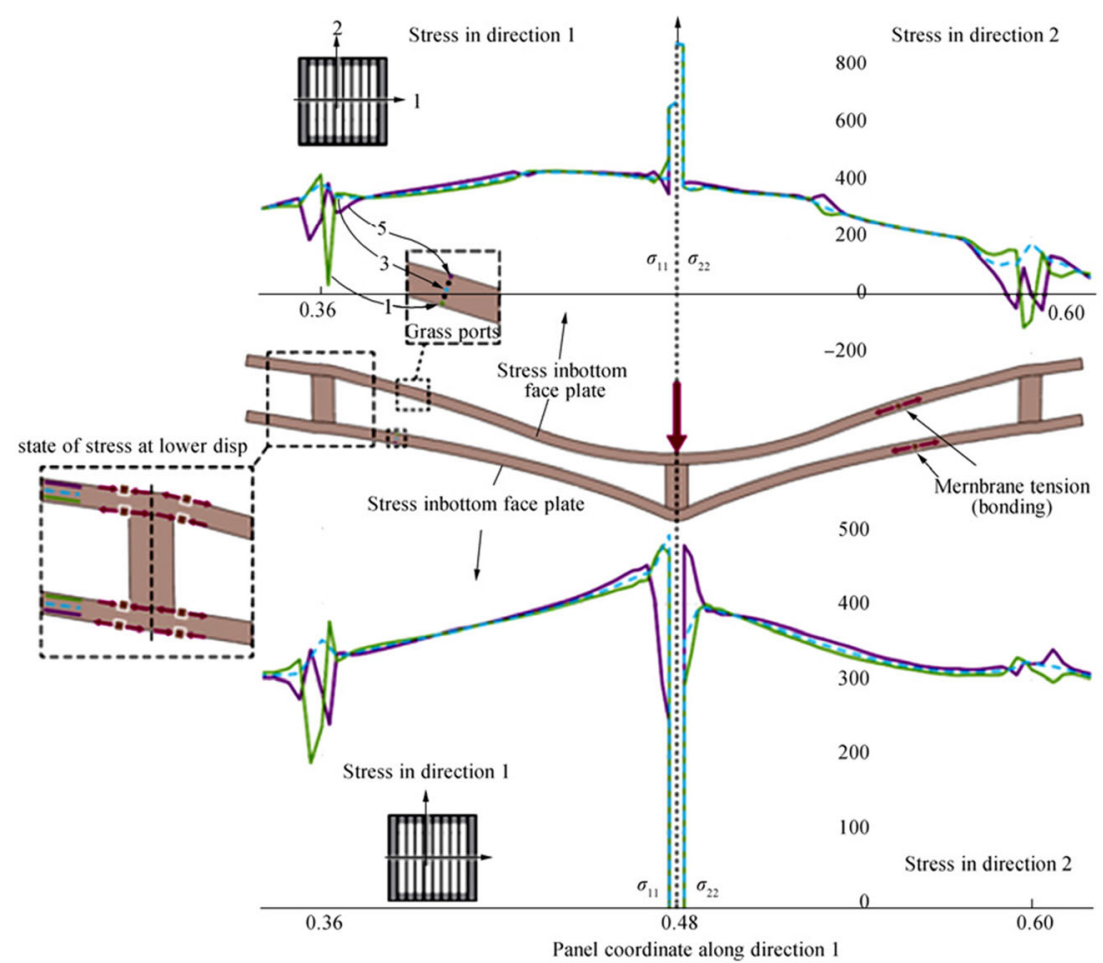


Figure 7 Tensile tests for base materials with different stress triaxialities (reproduced from Kõrgesaar et al. 2018a)

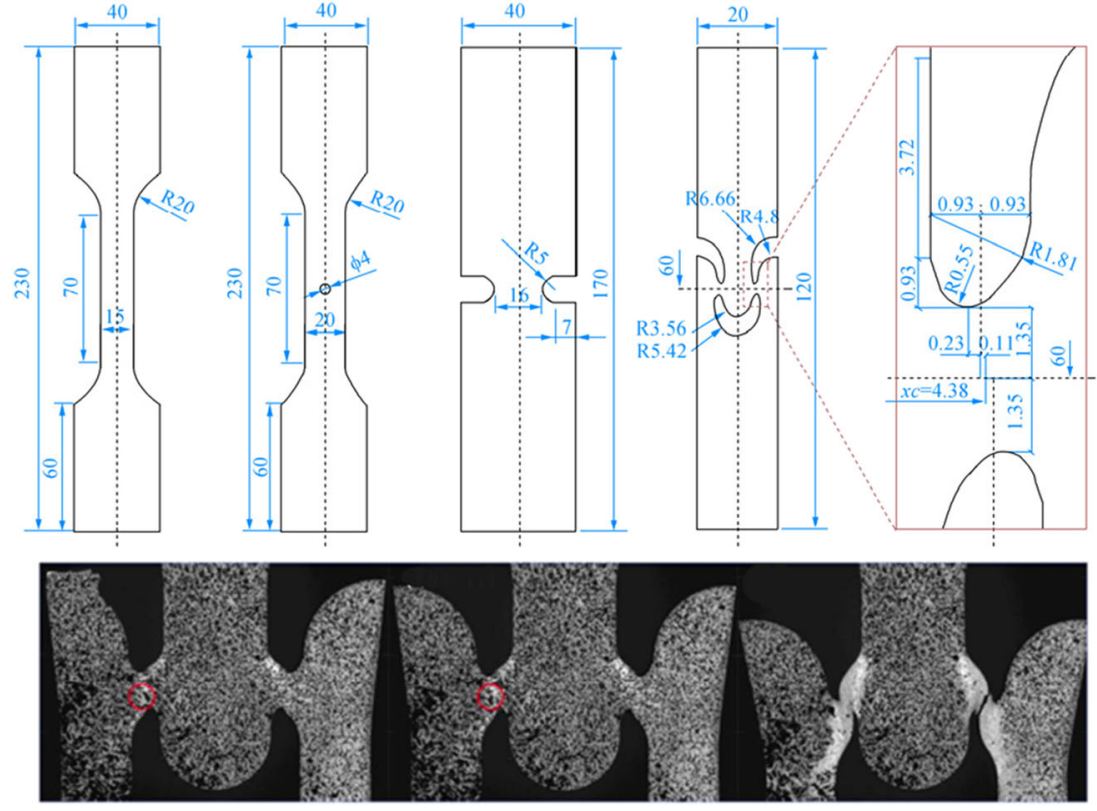

ranged from $0.2 \mathrm{~mm} / \mathrm{min}$ to $2 \mathrm{~mm} / \mathrm{min}$, depending on the specimen. During testing, the force (using load cell) and displacement (MTS) were recorded along with the displacement fields on one side of the specimen surface were measured with a high-resolution (2 Mpxl) digital camera Lavision Imager Pro $\mathrm{X} 2 \mathrm{M}$ equipped with $105 \mathrm{~mm}$ Nikon lens at a frequency of $2 \mathrm{~Hz}$. The images were post-processed using a LAVISION digital image correlation (DIC) software to acquire local displacement and strain data. It was observed that the speckle pattern produced by both printing and by paper separated from the specimens close to the point of fracture (see Figure 8). FE simulations are presented in Kõrgesaar et al. (2018a) and reviewed in Figure 8 to highlight the challenges in Finite Element simulations.

\subsection{Results and Experimental Observations}

The base material properties for different triaxialities are presented in Figure 8. The general observation is that the stressstrain curves per specimen type show good repeatability. All tensile experiments show localization of damage, meaning that we cannot neglect the necking phenomenon. Necking happens in the weakest section of the specimens, as it should. It is also clear from the experiments that stress triaxiality affects the entire engineering stress-strain curve, not just the softening part of the curve. The central hole and standard dog-bone specimen display diffuse type of necking with localization through the width of the specimen. The damage progressed gradually until the final fracture. Notched specimens display localized necking through-thickness. It is noteworthy that it is challenging to exactly define the location and time instance of the fracture onset because fracture initiates inside of the specimen where triaxiality is the highest and then grows towards the specimen surfaces. Moreover, in most of the specimens, the fracture propagation after onset shows rapid development except in the case of central hole specimen that exhibits significant softening. Thus, the sources of uncertainty in experiments are mainly due to variations in material properties, but also due to specimen shape that affects the failure strains.

\subsection{Consequences to the Material Modeling Uncertainties in FE Simulations}

These observations have a significant impact on the modeling of the stress-strain curves in the Finite Element simulations, as the models must incorporate changes in plastic, monotonically increasing part of the stress-strain curve as well as the softening part. In addition, as the experiments are based purely on membrane state instead of bending, the applicability of the material behavior in general becomes an open question in cases where the structural members of the panels are exposed to a significant amount of bending (see for example Woelke et al. 2018; Costas et al., 2019). This case rises in sandwich panel type of closed structures where the unit cells are exposed to warping (Romanoff and Varsta, 2007; Karttunen et al. 2019).

\section{Weld Material Experiments}

\subsection{Test Set Up}

Welds cause changes into material microstructure and can induce residual stresses to the specimens. These can have a significant effect on behavior of the structure in terms of 
Figure 8 Tensile tests results and FE simulations for base materials with different stress triaxialities (reproduced from Kõrgesaar et al. 2018a)
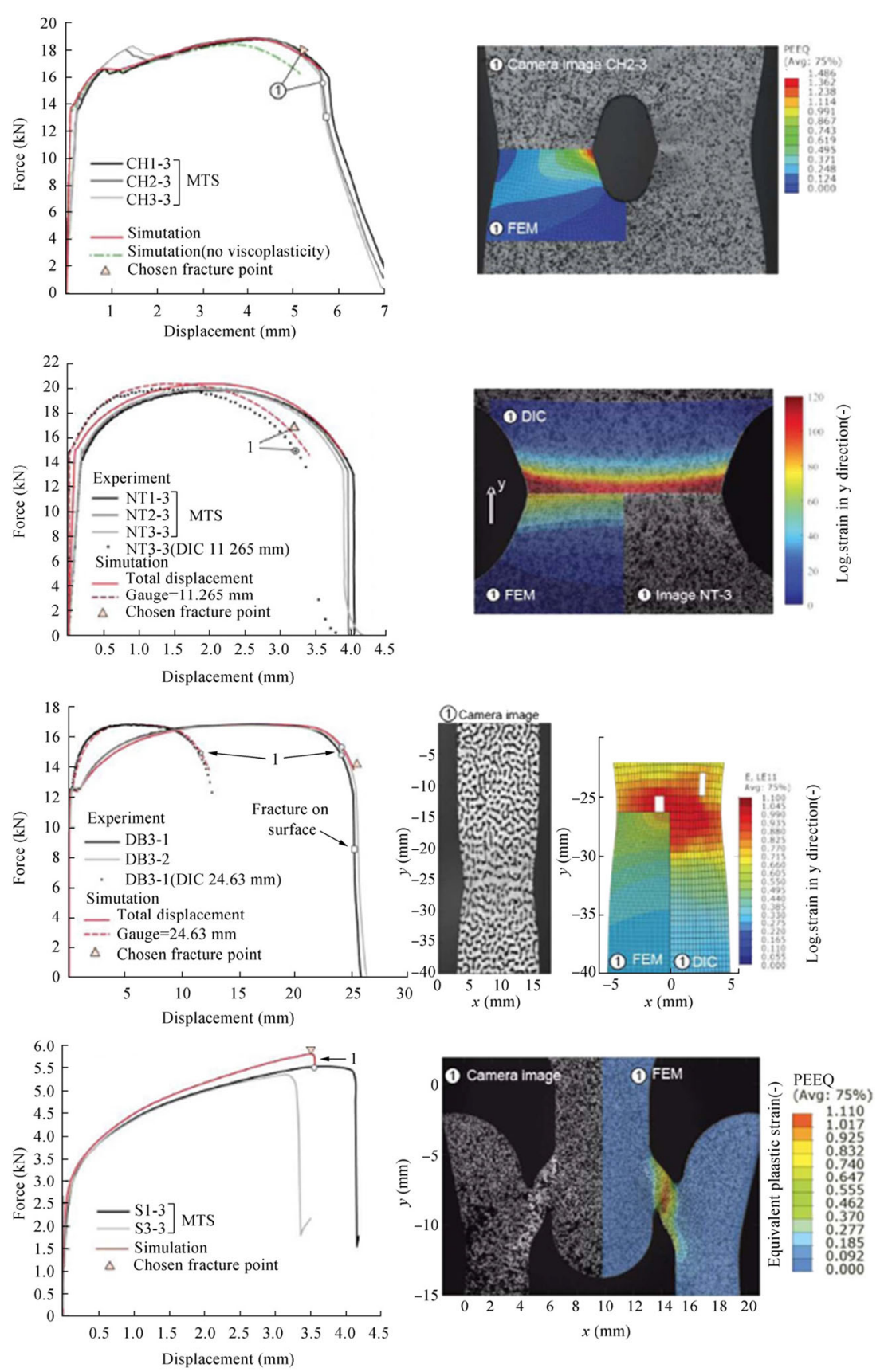

ductility. Therefore, standard Vickers hardness measurements were performed on stake weld cross-section to identify changes in material strength (Romanoff et al. 2006; Jutila 2009; Korrgesaar et al. 2016) and the material gradient observed in the panels. Furthermore, the ultimate strength tests in tension (Jutila 2009) and bending (Romanoff et al. 2006) were performed in order identify the load-carrying mechanism and load-response behavior of the joints (see Figure 9). These two loading modes interact in the panels. Due to experimental limitations, the Digital Image correlation system was applied to the tensile ultimate strength experiment, while in the bending experiment only the load and deformation were measured. In the hardness measurements, both $1.5 \mathrm{~mm}$ and $3 \mathrm{~mm}$ face plates and $3 \mathrm{~mm}$ and $4 \mathrm{~mm}$ web plates were considered. While the steel of the panel tests was S235JR, in ultimate strength tests of the welds it was S355J2G2 due to different manufacturer of the panels. This difference does not affect the qualitative experimental findings.

Tensile tests were done for welds cut from the sandwich panels and by strengthening the weld that is not under investigation with fillet welds (Jutila 2009). The supporting structure was based on $10 \mathrm{~mm}$ and $15 \mathrm{~mm}$ structural steel plates 

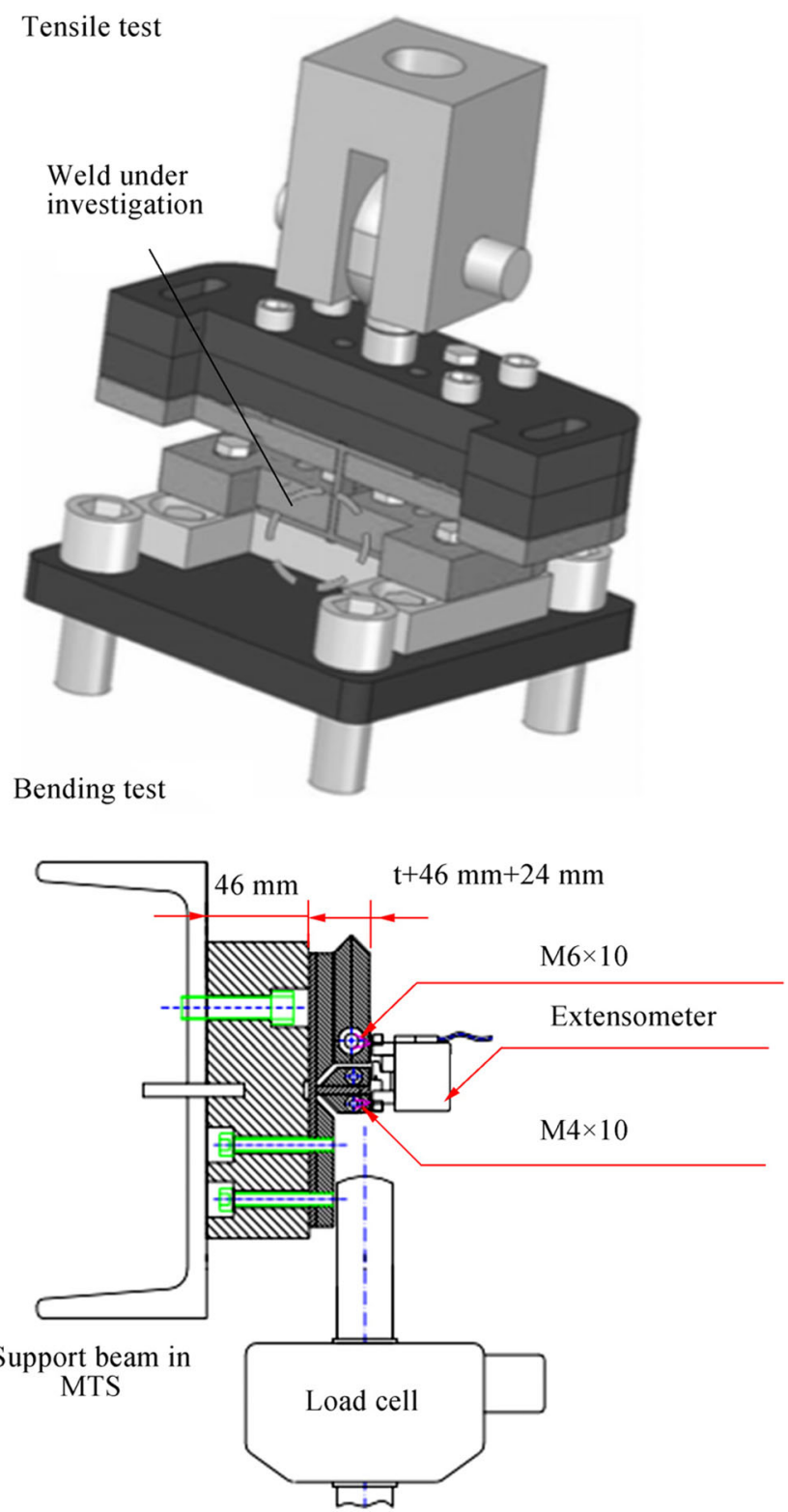

Figure 9 Tensile and bending experiments for laser-welds (modified from Romanoff et al. 2006; Jutila 2009)

that were supporting the faceplate so that it remains mostly undeformed and does not cause friction to the web of the loaded specimen. The force cylinder was Wärtsilä 45860 , the controlling displacement transducer HBM W50 and the force cylinder HMB 100kN U2B. In these tests, the Digital Image Correlation system of ARAMIS is used. The data acquisition system DAP2500a was by Microstar Laboratories.

In bending tests, the ultimate strength was measured by removing one of the faces of the sandwich panel and by restraining the bending deformations of both faces and webs by additional support plates attached to the specimen by M6x20 and M4x10 bolts. This allowed measurement of the displacement with extensometer INSTRON1343 at initial stages and by displacement sensor of the Instron 1343 axial- torsion testing machine at later stages. The load sensor of the Instron 1343 testing device measured the load. The supporting structure, C200, profile was attached to the pillars of this material testing frame.

Both tensile and bending tests were performed by increasing the loading monotonically until the specimen broke or until the maximum measuring capacity of the system was reached.

\subsection{Weld Geometrical and Material Properties}

The hardness profiles of the specimens are shown in Figure 10 for the specimens from Jutila (2009) and Kõrgesaar et al. (2018a).

The profiles measured for different sets of specimens are very similar in general and show that the stake weld penetrates vertically to the web plate by more than the plate thickness is. However, the penetration is not for the full width of the web, meaning that there exist two crack-like defects at both sides of the weld. As can be seen from Figure 10 the hardness is within
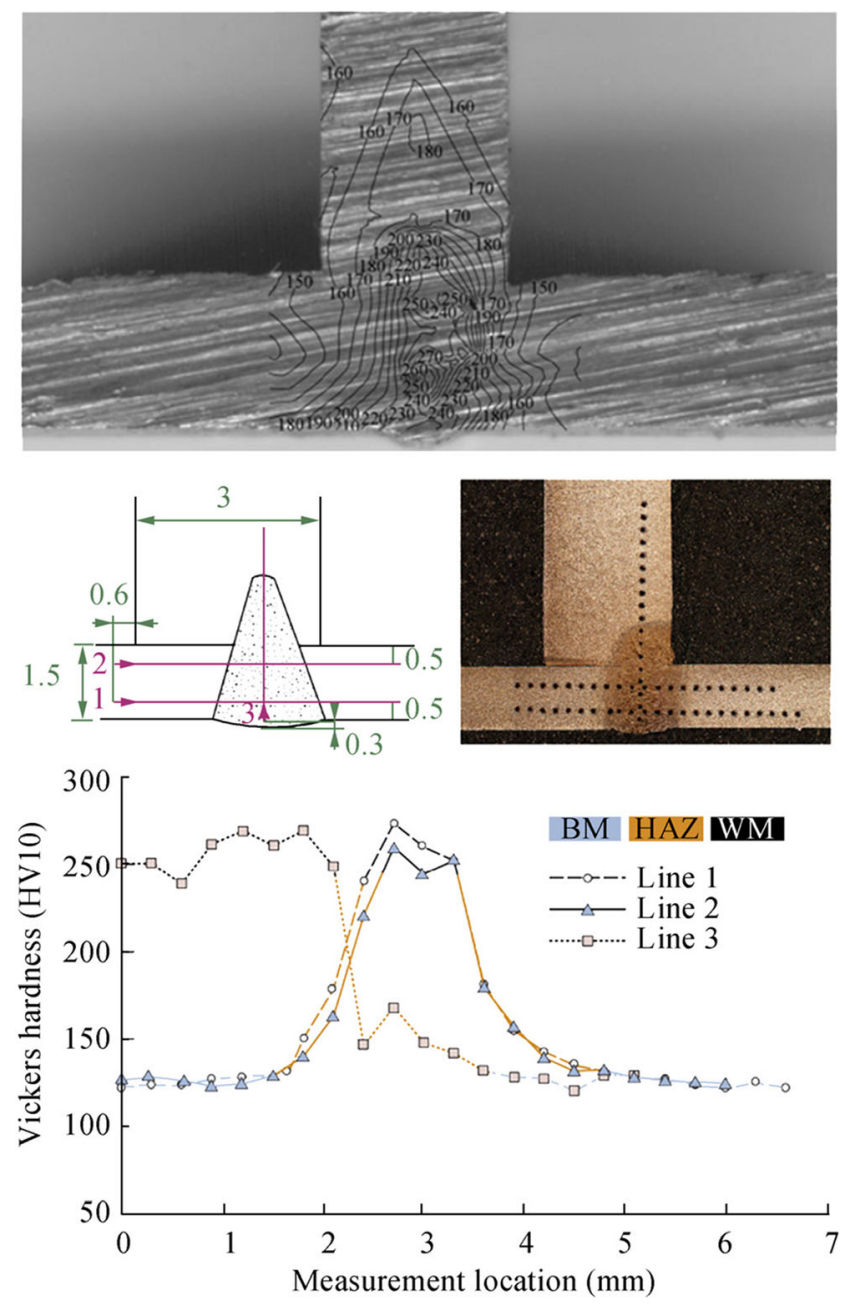

Figure 10 Hardness profile measured of laser-welds (reproduced from Jutila 2009; Kõrgesaar et al. 2018a) 
the limits of the classification societies and it have very rapid change between base and weld material since the heat-affected zone, HAZ, is less than $1 \mathrm{~mm}$ in width. This is an indication of a significant material gradient due to the welding process. The different type of weld positioning of different panels is shown in Figure 11. It is clear from this figure that the crack-like defects are not always symmetric with respect to the weld mid-line, indicating that the moment-curvature relation of the T-joint can be asymmetric due to a contact (e.g., Boronski and Szala 2006; Romanoff et al. 2007).

\subsection{Results and Experimental Observations}

The strength of welds in tension is highly localized in the heataffected zone (see Figure 12). It should also be noted that the notches at both sides of the welds do not act as the initial cracks leading to final failure, but rather as crack initiation points. This is due to fact that the differences in material properties over the weld interact with this geometrical feature. Thus, these notches act as damage localization sites, but not as indicators for direction of the crack path. As can be seen from the specimen the damage localizes there and microrotation, associated with shear, is seen to occur at the point of failure. This is an indication of non-locality in terms of classical and non-classical continuum mechanics (e.g., de Borst 1990; Bazant and Jirasek 2002, Srinivasa and Reddy 2017). The DIC pattern used is removed due to this just before the final fracture. It should also be noted that the response of the specimen is monotonically increasing until the fracture and the plastic region of the specimen is very small in comparison to the base materials. The bending tests show a different behavior (see Figure 13). There the force-displacement or moment-slope behavior is non-linear and significant plastic region is observed. Moreover, due to the different position
Figure 11 Different types of stake welds observed in panels (reproduced from Romanoff et al. 2006)

\section{Center weld. incomplete web penetration}
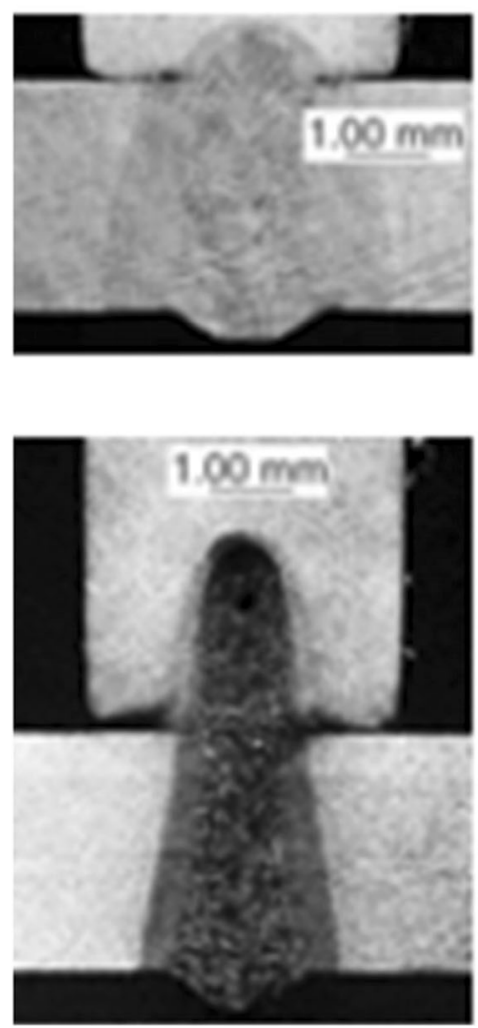

Center weld,very deep web penetration

\section{Center weld, significant root-gap}
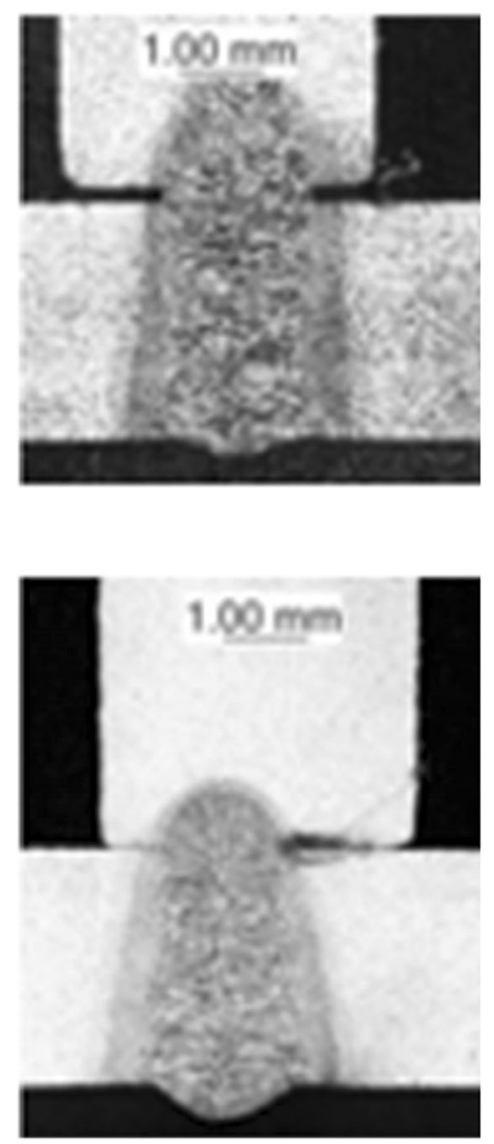

Off-center weld, insignificant root-gap 
Figure 12 Tensile tests for weld materials (modified from Jutila 2009)
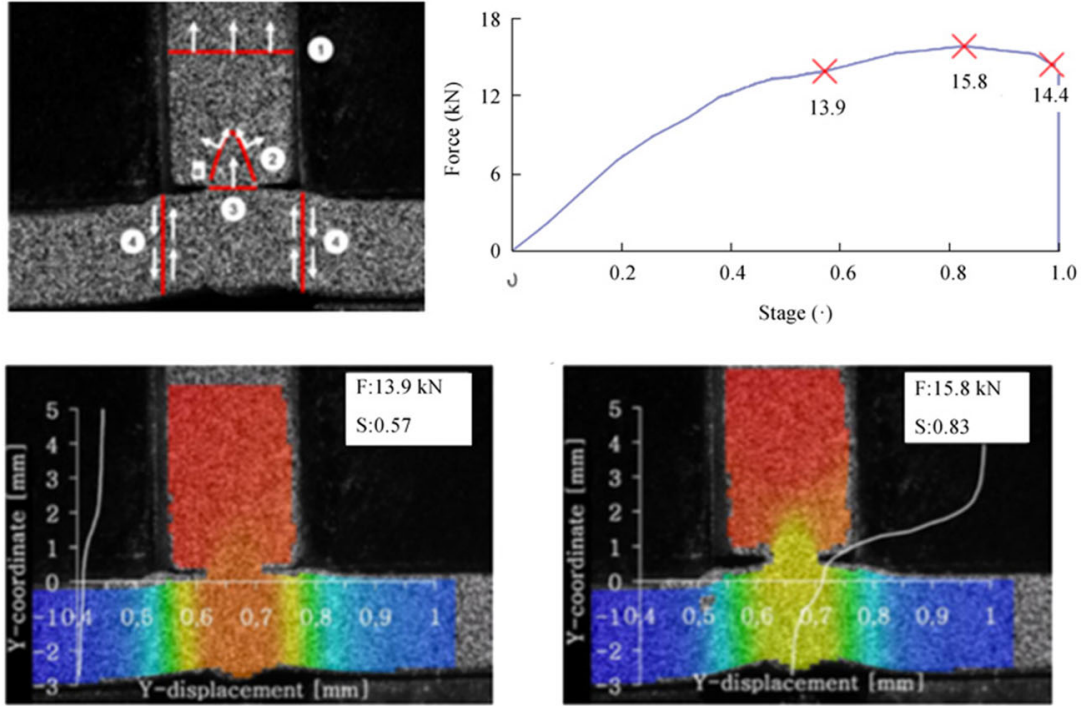

Strain in Vertical Y-direction

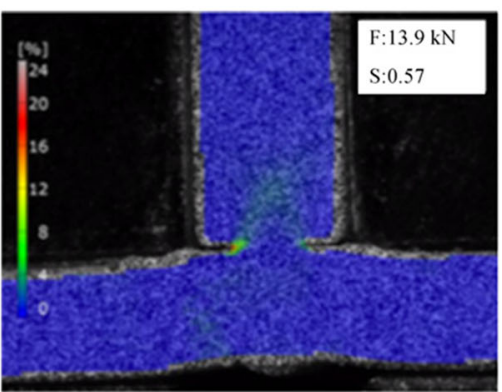

Shear Strain in XY-direction
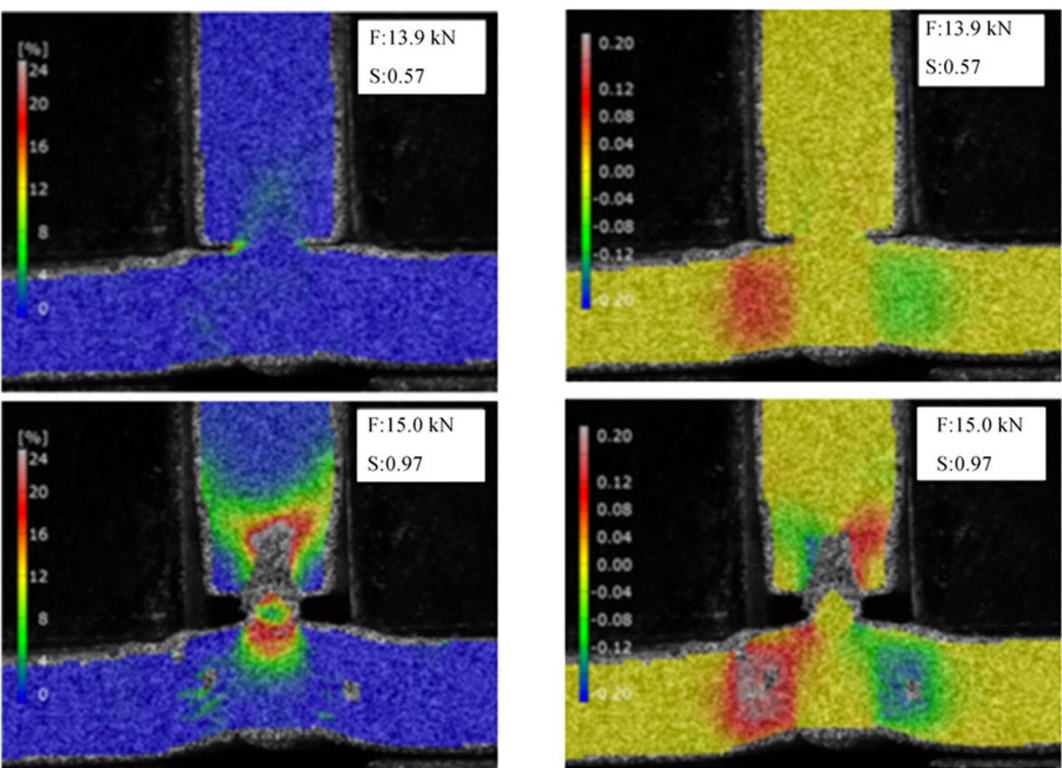

of the welds, the repeatability of the experiments is poor. This uncertainty is caused by contact which varies considerably between specimens.

It is clear that the differences are due to the possible contact at the neighborhood of the weld but also due to the different widths of the welds. Furthermore, in these experiments welds do not fail due to fracture, but form a plastic hinge. These observations indicate that although the unit cells warp in sandwich panel experiments and expose the welds to bending, the rapid micro-cracking at low load levels is not only the result of the bending but also the shear type of stress state that is more critical in sandwich panels than in stiffened plates. The reason can be that only a few unit cells deform in the sandwich panels while the stiffened panels deformed more globally. Due to this, the shear force, $Q_{x}$, along the stiffener is higher in sandwich panels, which can result in the rapid, almost catastrophic, failure of welds. This in combination with high shear force, $Q_{y}$, makes the welds highly loaded. This rationalization of sandwich panel behavior is a clear indication of strong non-linear interaction between material, structural and loading gradients.

\subsection{Aspects on Finite Element Modeling}

The above observations suggest that welds and possible contacts should be modeled in great detail in FEA that poses a significant challenge (see Figure 13). This requires solid element mesh, which increases mesh size significantly, because we have thin-walled structure where some of the phenomena are truly $3 \mathrm{D}$ close to the welds. Another aspect is the microrotation at the welds. Current FE-codes based on classical continuum mechanics cannot capture these microrotations, 
Figure 13 Bending tests for weld materials (modified from Romanoff et al. 2006)
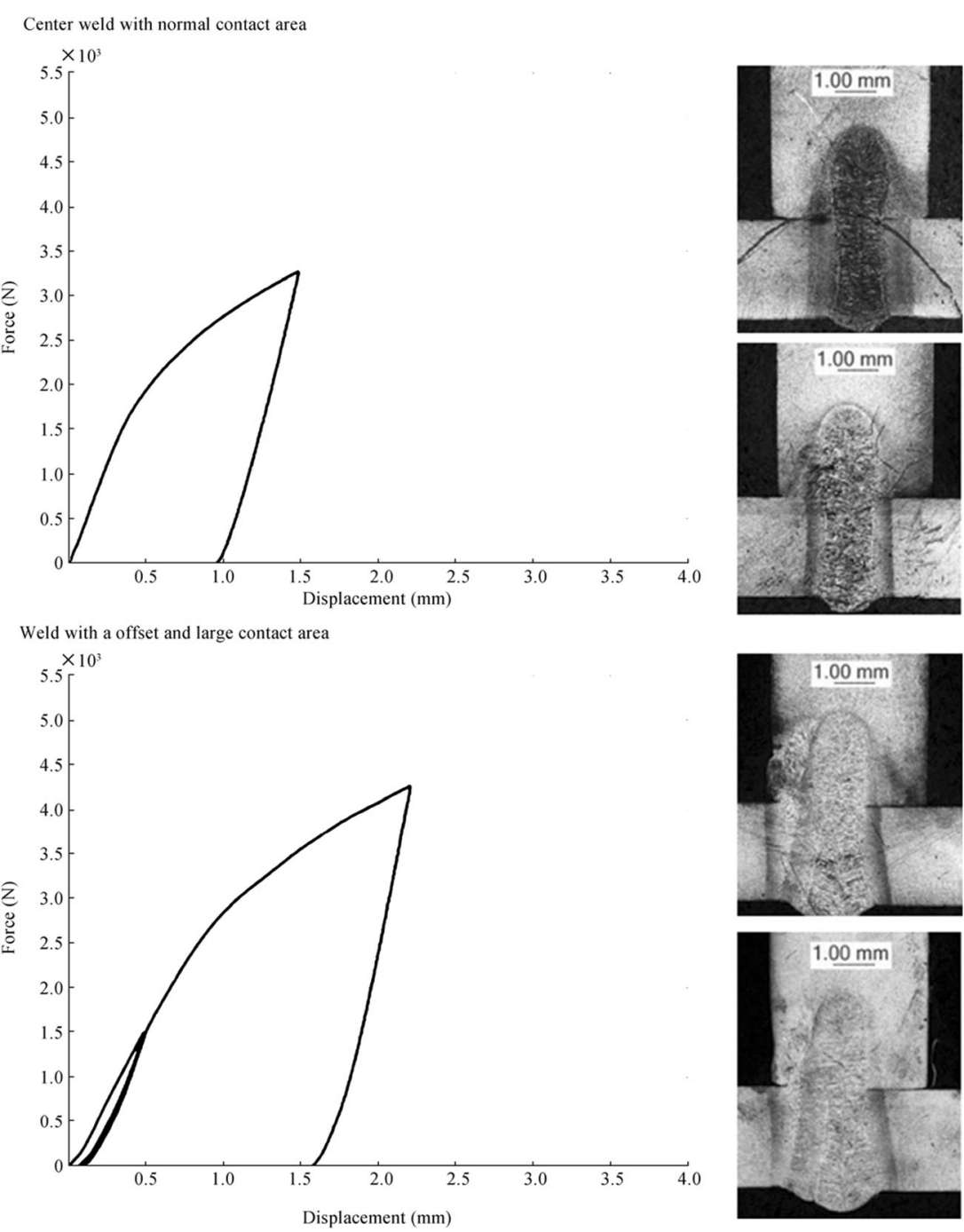

which leads to mesh size dependency and "size effect" on the damage. This fundamental issue could be overcome by elements size-dependent weld strength criteria. However, as the base material experiments and simulations show, this is a challenge already for the homogenous base materials undergoing both membrane and bending actions. In welds, we need to consider in addition the heterogeneous material distribution, uncertainty in micro geometry, micro rotations and contacts making development of such criterion very challenging. Thus, there is need for properly working finite element based on non-classical continuum mechanics that allow material rotation and modeling of these effects.

\section{Discussion of the Challenges Observed}

The paper investigated experimental observations regarding the failure of quasi-statically loaded laser-welded stiffened and sandwich panels. We aimed to identify the structural and material failure modes both qualitatively and quantitatively. The paper aimed to highlight the challenges we have in finite element simulations and how to tackle those to increase the fidelity of simulations. The discussion was based on the experimental observations with panels investigated at the length scale of real structures, base materials, and welded joints. The focus was on the experimental classification of the phenomena based on loading, structural, and material gradients. We discuss each of these aspects next while reflecting on potential challenges related to numerical simulations; the summary is visualized in Figure 14.

The loading gradient was investigated by positioning the spherical indenter to different positions in a square panel. Theoretically, at the initial, zero load level, the panel response is defined by bending stiffness that includes both stiffness against bending moments and out-of-plane shear forces. As the panel is square, the geometry does not affect the loading gradient, but the orthotropy, position of the loading, and the boundary conditions will affect to a large degree. The role of the orthotropy is to define the share of loading carried out in principal, stiffener direction and transverse to it. In the panels 


\begin{tabular}{|c|c|c|}
\hline Experimental observation & Numerical challenge & Possible solutions \\
\hline $\begin{array}{l}\text { - Rapid panel failure and load-drops due to } \\
\text { simultaneous load, stuctural and material } \\
\text { gradients (c.g. welds) } \\
\text { - This results in early shift of load-carrying } \\
\text { mechanism from bending to membrane actions }\end{array}$ & $\begin{array}{l}\text { FE-discretization becomes function of } \\
\text { localization of damage (space and time), } \\
\text { which make the assessment of new } \\
\text { structural designs a challenge in terms of } \\
\text { uncertainty }\end{array}$ & $\begin{array}{l}\text { - Mesh refinements needed at the location of } \\
\text { simultaneous load, structural and material } \\
\text { gradients } \\
\text { - Fine spatial and temporal discretization in } \\
\text { FE-mesh }\end{array}$ \\
\hline $\begin{array}{l}\text { - At base material tests necking is almost } \\
\text { impossibe to omit (violated plane stress } \\
\text { assumption) and failure initiates inside the } \\
\text { specimen (DiC provides only surface strains) }\end{array}$ & $\begin{array}{l}\text { Unified material model that accounts for } \\
\text { mesh size, stress triaxiality, hardening and } \\
\text { softening under combined membrane stretch } \\
\text { and bending in needed }\end{array}$ & $\begin{array}{l}\text { Multiscale models for material and } \\
\text { strucutal strength modeling }\end{array}$ \\
\hline $\begin{array}{l}\text { - Micro-rotations observed at the welds when } \\
\text { exposed to pure tension/shear and contates } \\
\text { observed when in bending }\end{array}$ & $\begin{array}{l}\text { - Need to model the welds with contact and } \\
\text { microrotation }\end{array}$ & $\begin{array}{l}\text { - Non-local solid elements needed at the } \\
\text { welds }\end{array}$ \\
\hline$\underbrace{400}_{300}$ & . & \\
\hline
\end{tabular}

Figure 14 Summary of the experimental observations, emerging challenges and possible solutions for numerical simulations of quasi-static collision experiments on laser-welded steel structures

selected, the orthotropy in shear stiffness is high, especially in the web-core sandwich panels. Due to this, significant part of the shear loads is carried in stiffened direction and significantly less in the opposite direction. As a result, the sandwich panels deform initially locally, activating only a few unit cells in the panel. This is highlighted by the fact that the sandwich panels have very high stiffness against bending and twisting moments, the panels deform mostly in shear in the weaker direction, opposite to stiffeners (e.g., Romanoff and Varsta 2007; Karttunen et al. 2019). This results in structural gradient due to stiffener rotation restraint. Due to structural gradient, the shear force, $Q_{y}$, causes high secondary bending to the faces, webs and welds, and as a result, the sandwich panels start to damage at very small load levels locally. This damage is affected by the material gradient observed at the region where base material properties change to weld properties through heat-affected zone. In stiffened panels, due to smaller bending capacity, the panels experience earlier membrane action and therefore deform more globally. When loading is moved closer to the edge of the plate or away from the stiffeners, the shear force gradient increases considerably, and the failure starts earlier due to increased secondary bending. These phenomena are related to low load levels. As the panels deform at higher load levels, both of them deform under membrane actions. However, at this stage the local damage of sandwich panels has already spread and changed the loadcarrying mechanism considerably. From residual strength viewpoint, the mechanism is uncertain as the stiffeners have separated from the faceplates to some degree. This way they do not stiffen the plates anymore. Thus, if the collision or grounding damage is followed by in-plane compressive load induced by hull-girder bending, the stiffeners would not provide any more vertical or rotational support. In sandwich panels, the failure mode is a very rapid sequence of events, meaning that the temporal resolution of experiment and simulations should be much higher than in stiffened panels.

The orthotropy at the panel level results in complex damage accumulation at the level of base materials and welds. The stress-strain curves obtained from membrane loading state with different triaxialities show different plastic parts of the stress-strain curves, which are even more different during the softening stage beyond necking. The benefit of softening in FEA context is that the element removal is not sudden, and thus there is a possibility to redistribute the stresses when damage progresses (e.g., Abubakar and Dow 2013; Körgesaar and Romanoff 2013. These localized phenomena can be incorporated into effective stress-strain curves, but these should be modified by the element size, strain state and rate and stress triaxiality to reach good agreement between large-scale simulations and the damage. In addition, the models should be extended to stress states including compression and to account the effects of bending and its influence on the through-thickness strain and stress distributions on shell and solid elements. These issues could be dealt with multiscale modeling techniques of materials science, which allow direct simulation of material strength under complex loading scenarios (e.g., Geers et al. 2019; Matous et al. 2017). However, these techniques increase the computational tasks 
significantly. The issue could be handled by parallel computing or by developing new models for material failure based on typical observed load paths (e.g., strain paths) from thinwalled structures. Additional complex damage component arose due to micro rotations associated with shear in the welds and heat-affected zone (HAZ). Current FE-codes based on classical continuum mechanics cannot models such effects and need to be extended to handle non-classical continuum mechanics formulations, which account for these higher-order deformations. The main benefit of these formulations is that the size dependency of the FE-solution is handled with much better convergence rates, giving a chance for engineers to model the complex phenomena with better confidence (e.g., de Borst 1990; Srinivasa and Reddy 2017).

The paper was limited by sample size and the fact that experiments were quasi-static. Despite the quasi-static loading, some observed phenomena were rapid and thus, the strain rates should be measured, especially during fracture onset directly from the surface of the structure and possibly also from inside. DIC was not successfully used in panel level, but worked out in material scale experiments, in 2D, as there are no curvature end deformations are uniform stretches. In cases of micro rotation or significant distortion, it is clear that better DIC patterns are needed, which stick on the specimen until fracture occurs and beyond. The experiments reveal that there is non-locality both in panels and in welds. ESL (e.g., Reinaldo Goncalves et al., 2019; Namaplly et al. 2019) and solid Finite elements with this effect are emerging and clearly would improve the predictions significantly. These aspects are left for future work, but it is clear that there is a need for these developments.

Ultimate residual strength and opening size are critical aspects in marine structures after collision or grounding has occurred. Present paper shows that the damage shapes are different in stiffened panels, although the force-displacement curves are practically the same to the point of fracture. In the case of sandwich structures, the differences are seen already at the forcedisplacement curves. This certainly affects the opening size and the flooding following the damage. The flow rates through damages in stiffened single skin panels and the double skin type sandwich panels are clearly a difficult flow problem that needs research for different opening shapes and sizes resulting from experiments. Another aspect is the residual strength after the damage. Carrying the compressive loads might be problematic for sandwich panels that have lost their structural integrity, in contrast to stiffened panels that are still intact in terms of faceplate to stiffener connection. Thus, the stiffeners are still providing strength against plate buckling, while in sandwich panels this assumption does not hold. This would affect the load-carrying capacity of the structure significantly. In tension, the complex, localized fracture patterns would lead to different global fracture processes of the structures. Both compression and tension would need further research on prevailing failure modes under these basic load conditions.
A recent study by Berntson et al. (2019) on sandwich panels shows that when welds are explicitly included in FEA based optimization with evolutionary algorithms, the optimized structure becomes insensitive to the material and structural gradients. Thus, a robust design is obtained that is less sensitive to these loading, material and structural gradients. If the optimization is done without the weld, the result is very sensitive to these gradients. This is a sign that modern computational optimization techniques are able to find wellperforming structures if the modeling is carried out in a right manner. This is, at the same time, a threat and an opportunity. A threat, as the designers may become over-confident with their designs and not checking the structures carefully for complex interactions between the structure, loading, manufacturing processes, scenario definition, and materials selection. It is also an opportunity as if the modeling is done correctly, and we understand the failure processes in-depth, we can leave the optimization for computers with the aim to find a robust, well-performing structure.

\section{Conclusions}

The aim of this paper was to review the lessons learned from quasi-static collision experiments made by authors on laserwelded steel thin-walled structures, with aim to highlight the challenges for numerical simulations based on Finite Element Method. The panels tested had to various degrees, differences in gradients of material distribution, structural continuity and loads or boundary conditions. These gradients were used to describe the changes in load-carrying mechanism of the panels and were shown to have a significant impact on the way the load is carried. The experiments show that the stiffened panels perform predictably and the force-displacement curve is monotonically increasing, while in sandwich panels, sudden drops are observed, and the behavior is less predictable. These drops are due to complex, interacting load-carrying mechanisms that consist of load, material, and structural gradients. It is also seen that the failure mode in welds localizes through material rotation, which is impossible to model with classical continuum mechanics in detail and instead non-classical continuum mechanics are needed. These observations indicate that there is room for better computational techniques that can handle both spatial and temporal scales more accurately and effectively than today.

Acknowledgments The experimental program would not have been possible without the funding by the 100-Year Foundation of the Federation of Finnish Technology Industries and the Scientific Advisory Board for Defense. The analyses were carried out in project called Ultra Lightweight and Fracture Resistant Thin-Walled Structures through Optimization of Strain Paths, by the Academy of Finland (310828). This work was also supported by the Estonian Research Council grant PSG526. 
Funding Open access funding provided by Aalto University.

Open Access This article is licensed under a Creative Commons Attribution 4.0 International License, which permits use, sharing, adaptation, distribution and reproduction in any medium or format, as long as you give appropriate credit to the original author(s) and the source, provide a link to the Creative Commons licence, and indicate if changes were made. The images or other third party material in this article are included in the article's Creative Commons licence, unless indicated otherwise in a credit line to the material. If material is not included in the article's Creative Commons licence and your intended use is not permitted by statutory regulation or exceeds the permitted use, you will need to obtain permission directly from the copyright holder. To view a copy of this licence, visit http://creativecommons.org/licenses/by/4.0/.

\section{References}

Abubakar A, Dow RS (2013) Simulation of ship grounding damage using the finite element method. Int J Solids Struct 50(5):623-636. https:// doi.org/10.1016/j.ijsolstr.2012.10.016

Alsos HS, Amdahl J (2009) On the resistance to penetration of stiffened plates, part I-experiments. Int J Impact Eng 36(6):799-807. https:// doi.org/10.1016/j.ijimpeng.2008.10.005

Alsos HS, Amdahl J, Hopperstad OS (2009) On the resistance to penetration of stiffened plates, part II: numerical analysis. Int J Impact Eng 36(7):875-887. https://doi.org/10.1016/j.ijimpeng.2008.11.004

Barsoum I, Faleskog J (2007) Rupture mechanisms in combined tension and shear-experiments. Int J Solids Struct 44(6):1768-1786. https://doi.org/10.1016/j.ijsolstr.2006.09.031

Bazant ZP, Jirasek M (2002) Nonlocal integral formulations of plasticity and damage. J Eng Mech 128(11):1119-1149

Berntson K, Körgesaar M, Reinaldo Goncalves B and Romanoff J (2019) The influence of modelling weld effects when optimizing thinwalled structures for crashworthiness. Proceedings of the 29th International Ocean and Polar Engineering Conference ISOPE2019 Conference, Honolulu, HI, USA, June 16-21, 2019: 280-4287

Boronski D, Szala J (2006) Test of local strains in steel laser-welded sandwich structure. Polish Maritime Research, Special Issue, 31-36

Calle MAG, Salmi M, Mazzariol LM, Kujala P (2020) Miniature reproduction of raking tests on marine structure: similarity technique and experiment. Eng Struct 212:110527. https://doi.org/10.1016/j. engstruct.2020.110527

Choung J, Shim CS, Song HC (2012) Estimation of failure strain of EH36 high strength marine structural steel using average stress triaxiality. Mar Struct 29(1):1-21. https://doi.org/10.1016/j.marstruc.2012.08. 001

Costas M, Morin D, Hopperstad OS, Børvik T, Langseth M (2019) A through-thickness damage regularisation scheme for shell elements subjected to severe bending and membrane deformations. J Mec Phys Solids 123:190-206

de Borst R (1990) Simulation of strain localization-a repraisal of the Cosserat continuum. Eng Comput 8:317-332

Dunand M, Mohr D (2014) Effect of Lode parameter on plastic flow localization after proportional loading at low stress triaxialities. J Mech Phys Solids 66(1):133-153. https://doi.org/10.1016/j.jmps. 2014.01.008

Ehlers S, Varsta P (2009) Strain and stress relation for non-linear finite element simulations. Thin-Walled Struct 47(11):1203-1217. https:// doi.org/10.1016/j.tws.2009.04.005

Ehlers S, Tabri K, Romanoff J, Varsta P (2012) Numerical and experimental investigation on the collision resistance of the X-core structure. Ships Offshore Struct 7(1):21-29. https://doi.org/10.1080/ 17445302.2010.532603
Fleck NA, Deshpande VS (2004) The resistance of clamped sandwich beams to shock loading. J Appl Mech 71(3):386-401

Frank D, Romanoff J, Remes H (2013) Fatigue strength assessment of laser stake-welded web-core steel sandwich panels. Fatigue Fract Eng Mater Struct 36(8):724-737. https://doi.org/10.1111/ffe.12038

Frodal BH, Morin D, Børvik T, Hopperstad OS (2020) On the effect of plastic anisotropy, strength and work hardening on the tensile ductility of aluminium alloys. Int J Solids Struct 188-189:118-132. https://doi.org/10.1016/j.ijsolstr.2019.10.003

Geers MGD, Kouznetsova VG, Brekelmans WAM (2019) Multi-scale computational homogenization: trends and challenges. J Comput Appl Math 234:2175-2182. https://doi.org/10.1016/j.cam.2009.08. 077

Guedes Soares C, Basu R, Simonsen B.C, Egorov GV, Hung CF, Lindstrom P, Samuelides E, Vredeveldt A, Yoshikawa T (2009) Committee V.1. Damage assessment after accidental events, International Ship and Offshore Structures Congress, August 1621, 2009, Seoul, Korea, 2: 1-72

Haltom SS, Kyriakides S, Ravi-Chandar K (2013) Ductile failure under combined shear and tension. Int J Solids Struct 50(10):1507-1522. https://doi.org/10.1016/j.ijsolstr.2012.12.009

Hogström P, Ringsberg JW (2012) An extensive study of a ship's survivability after collision-a parameter study of material characteristics, non-linear FEA and damage stability analyses. Mar Struct 27(1):1-28. https://doi.org/10.1016/j.marstruc.2012.03.001

Hogström P, Ringsberg JW, Johnson E (2009) An experimental and numerical study of the effects of length scale and strain state on the necking and fracture behaviours in sheet metals. Int J Impact Eng 36(10-11):1194-1203. https://doi.org/10.1016/j.ijimpeng. 2009.05.005

Hoogeland M, Vredevelt AW (2017) Full thickness material tests for impact analysis verification. Progress in the Analysis and Design of Marine Structures - Guedes Soares \& Garbatov (Eds), 2017, 449-458 Taylor \& Francis Group, London, ISBN 978-1-13806907-7

Jones N (2013) The credibility of predictions for structural designs subjected to large dynamic loadings causing inelastic behaviour. Int $\mathrm{J}$ Impact Eng 53(1):106-114. https://doi.org/10.1016/j.ijimpeng. 2011.12.008

Jutila M (2009) Failure mechanism of a laser stake welded T-joint. M.Sc. thesis, Helsinki University of Technology, Department of Applied Mechanics

Karttunen AT, Reddy JN, Romanoff J (2019) Two-scale micropolar plate model for web-core sandwich panels. Int J Solids Struct 170:82-94. https://doi.org/10.1016/j.ijsolstr.2019.04.026

Körgesaar M, Romanoff J (2013) Influence of softening on fracture propagation in large-scale Shell structures. Int J Solids Struct 50(24): 3911-3921. https://doi.org/10.1016/j.ijsolstr.2013.07.027

Kõrgesaar M, Romanoff J (2014) Influence of mesh size, stress triaxiality and damage induced softening on ductile fracture of large-scale shell structures. Mar Struct 38(1):1-17. https://doi.org/10.1016/j. marstruc.2014.05.001

Körgesaar M, Remes H, Romanoff J (2014) Size dependent response of large shell elements under in-plane tensile loading. Int J Solids Struct 51(21-22):3752-3761. https://doi.org/10.1016/j.ijsolstr. 2014.07.012

Kõrgesaar M, Romanoff J, Palokangas P (2016) Penetration resistance of stiffened and web-core sandwich panels: experiments and simulations. Aalto University, Department of Mechanical Engineering, Finland. ISSN 1799-490X (pdf)

Kõrgesaar M, Romanoff J, Remes H (2017) Influence of material nonlinearity on load carrying mechanism and strain path in stiffened panel. Procedia Structural Integrity. 2nd International Conference on Structural Integrity, ICSI 2017, 4-7 September 2017, Funchal, Madeira, Portugal https://doi.org/10.1016/j.prostr.2017.07.050 
Kõrgesaar M, Romanoff J, Remes H, Palokangas P (2018a) Experimental and numerical penetration response of laser-welded stiffened panels. Int J Impact Eng 114(1):78-92

Kõrgesaar M, Romanoff J, Palokangas P (2018b) Experimental and numerical assessment of fracture initiation in laser-welded webcore sandwich panels. Eighth International Conference on, ThinWalled Structures - ICTWS 2018, Lisbon, Portugal, July 24-27. Ref. b

Kõrgesaar M, Romanoff J, Remes H (2019) Fracture modelling of large thin-walled structures. New trends in fatigue and fracture - NT2F19, October 8-10, 2019, Tucson, Arizona, USA

Li Y, Wierzbicki T (2010) Prediction of plane strain fracture of AHSS sheets with post-initiation softening. Int J Solids Struct 47(17): 2316-2327. https://doi.org/10.1016/j.ijsolstr.2010.04.028

Lou Y, Huh H, Lim S, Pack K (2012) New ductile fracture criterion for prediction of fracture forming limit diagrams of sheet metals. Int $\mathrm{J}$ Solids Struct 49(25):3605-3615. https://doi.org/10.1016/j.ijsolstr. 2012.02.016

Matous K, Geers MGD, Kouznetsova VG, Gillman A (2017) A review of predictive nonlinear theories for multiscale modeling of heterogeneous materials. J Comput Phys 330:192-220. https://doi.org/10. 1016/j.jcp.2016.10.070

Naar H, Kujala P, Simonsen BC, Ludolphy H (2002) Comparison of the crashworthiness of various bottom and side structures. Mar Struct 15(4-5):443-460. https://doi.org/10.1016/S0951-8339(02)00012-6

Namaplly P, Karttunen A, Reddy JN (2019) Nonlinear finite element analysis of lattice core sandwich beams. Eur J Mech / A Solids 74: 431-439. https://doi.org/10.1016/j.euromechsol.2018.12.006

Ohtsubo H, Kawamoto Y, Kuroiwa T (1994) Experimental and numerical research on ship collision and grounding of oil tankers. Nucl Eng Des 150(2-3):385-396. https://doi.org/10.1016/0029-5493(94) 90158-9

Östlund R, Oldenburg M, Häggblad HÅ, Berglund D (2015) Numerical failure analysis of steel sheets using a localization enhanced element and a stress based fracture criterion. Int J Solids Struct 56-57:1-10. https://doi.org/10.1016/j.ijsolstr.2014.12.010

Pedersen PT (2010) Review and application of ship collision and grounding analysis procedures. Mar Struct 23(3):241-262. https://doi.org/ 10.1016/j.marstruc.2010.05.001

Rabczuk T, Kim JY, Samaniego E, Belytschko T (2004) Homogenization of sandwich structures. Int J Numer Methods Eng 61:1009-1027

Reinaldo GB, Karttunen, A, Romanoff, J (2019) A nonlinear couple stress model for periodic sandwich beams. Compos. Struct 212: 586-597

Ringsberg JW (2010) Characteristics of material, ship side structure response and ship survivability in ship collisions. Ships Offshore Struct 5(1):51-66. https://doi.org/10.1080/17445300903088707

Romanoff J, Varsta P (2007) Bending response of web-core sandwich plates. Compos Struct 81(2):292-302. https://doi.org/10.1016/j. compstruct.2006.08.021

Romanoff J, Remes H., Socha G, Jutila M (2006) Stiffness and strength testing of laser stake welds in steel sandwich panels. Helsinki University of Technology, Ship Laboratory, Report M291. ISBN951-22-8143-0, ISSN 1456-3045

Romanoff J, Remes H, Socha G, Jutila M, Varsta P (2007) The stiffness of laser stake welded T-joints in web-core sandwich structures. Thin-Walled Struct 45(4):453-462. https://doi.org/10.1016/j.tws. 2007.03.008

Roth CC, Mohr D (2015) Ductile fracture experiments with locally proportional loading histories. Int J Plast 79(1):328-354. https://doi. org/10.1016/j.ijplas.2015.08.004
Rubino V, Deshpande VS, Fleck NA (2006) The dynamic response of Yframe and corrugated core sandwich beams. Eur J Mech A/Solids 28:14-24. https://doi.org/10.1016/j.euromechsol.2008.06.001

Schreuber M, Hogström P, Ringsberg JW, Johnson E, Janson CE (2011) A method for assessment of the survival time of a ship damaged by collision. J Ship Res 55(2):86-99

Simonsen BC, Törnqvist R (2004) Experimental and numerical modelling of ductile crack propagation in large-scale shell structures. Mar Struct 17(1):1-27. https://doi.org/10.1016/j.marstruc.2004.03.004

Srinivasa AR, Reddy JN (2017) An overview of theories of continuum mechanics with nonlocal elastic response and a general framework for conservative and dissipative systems. Appl Mech Rev 69: 030802-1-18

Sumi Y (2019) Structural safety of ships developed by lessons learned from the 100-year history of break-in-two accidents. Mar Struct 64: 481-491. https://doi.org/10.1016/j.marstruc.2018.12.003

Tabri K, Määttänen J, Ranta J (2008) Model-scale experiments of symmetric ship collisions. J Mar Sci Technol 13(1):71-84. https://doi. org/10.1007/s00773-007-0251-z

Tillbrook MT, Radford DD, Deshpande VS, Fleck NA (2007) Dynamic crushing of sandwich panels with prismatic lattice cores. Int J Solids Struct 44:6101-6123. https://doi.org/10.1016/j.ijsolstr.2007.02.015

Uppaluri R, Reddy NV, Dixit PM (2011) An analytical approach for the prediction of forming limit curves subjected to combined strain paths. Int J Mech Sci 53:365-373. https://doi.org/10.1016/j. ijmecsci.2011.02.006

Vredeveldt AW, Wevers LJ (1992) Full scale ship collision tests. First Joint Conference on marine Safety and Environment/Ship production, June 1-5. Delft University Press, Delft

Wadley HNG, Børvik T, Olovsson L, Wetzel JJ, Dharmasena KP, Hopperstad OS, Deshpande VS, Hutchinson JW (2013) Deformation and fracture of impulsively loaded sandwich panels. J Mech Phys Solids 61(2):674-699. https://doi.org/10.1016/j.jmps. 2012.07.007

Walters CL (2014) Framework for adjusting for both stress triaxiality and mesh size effect for failure of metals in shell structures. Int $\mathrm{J}$ Crashworthiness 19(1):1-12. https://doi.org/10.1080/13588265. 2013.825366

Werner B, Daske C, Heyer H, Sander M, Schöttelndreyer M, Fricke W (2014) The influence of weld joints on the failure mechanism of scaled double hull structures under collision load in finite element simulations. Procedia Mater Sci 3:307-312. https://doi.org/10.1016/ j.mspro.2014.06.053

Werner B, Heyer H, Sander M (2015) Numerical investigations of collision experiments considering weld joints. Eng Fail Anal 58:351368. https://doi.org/10.1016/j.engfailanal.2015.04.021

Wierzbicki T, Bao Y, Lee YW, Bai Y (2005) Calibration and evaluation of seven fracture models. Int J Mech Sci 47(4-5):719-743. https:// doi.org/10.1016/j.ijmecsci.2005.03.003

Woelke PB, Abboud NN (2012) Modeling fracture in large scale shell structures. J Mech Phys Solids 60(12):2044-2063. https://doi.org/ 10.1016/j.jmps.2012.07.001

Woelke PB, Shields MD, Abboud NN, Hutchinson JW (2013) Simulations of ductile fracture in an idealized ship grounding scenario using phenomenological damage and cohesive zone models. Comput Mater Sci 80(1):79-95. https://doi.org/10.1016/j. commatsci.2013.04.009

Woelke PB, Londono JG, Knoerr LO, Dykeman J, Malcolm S (2018) Fundamental differences between fracture behavior of thin sheets under plane strain bending and tension. IOP Conf Ser Mater Sci Eng 418:1-7. https://doi.org/10.1088/1757-899X/418/1/012078 